\title{
A semiótica das paixões e a análise da dimensão passional dos enunciados
}

\section{The semiotics of passions and the analysis of the passional dimension of discourse}

Eliane Soares de Lima

Universidade de Franca (UNIFRAN)

li.soli@hotmail.com

Resumo: Adotando uma perspectiva diacrônica, a intenção deste artigo é a de apresentar os desenvolvimentos teóricos e metodológicos que têm marcado o estudo das paixões dentro do quadro geral da semiótica de linha francesa. Interessa a partir daí retomar os apontamentos que assinalaram a chamada "virada fenomenológica" da teoria - enquanto momento no qual a preocupação com o sensível, com as condições de emergência do sentido, passa a ocupar o centro da atenção dos semioticistas - e discutir os desafios impostos, a necessidade de contínua evolução do modelo de análise criado para dar conta desse outro universo de significação. Assim, com base nos desdobramentos mais recentes da teoria, agora voltados à problemática da enunciação, do sentido configurado em ato, propõe-se uma reformulação do esquema passional canônico tal como concebido no livro Semiótica das paixões, de Greimas e Fontanille.

Palavras-chave: semiótica; paixões; dimensão passional; modalidades; tensividade.

Abstract: Adopting a diachronic perspective, the aim of this article is to present the theoretical and methodological developments that have characterized the study of passions within the general framework of French Semiotics. From this perspective, we'd like to go back to the 
writings which have marked the so-called "phenomenological turn" of the theory - as the moment when the concern with the sensitive, with the conditions of meaning emergence, becomes a major issue for semioticians - and discuss the challenges inflicted, the need of a constant evolution on the pattern of analysis created in order to examine this alternative universe of signification. Thus, based on the theory's most recent developments, having to do with enunciation, with meaning set up in act, we propose a reorganization of the canonical pathemic schema as featured in Greimas and Fontanille's Sémiotique des passions.

Keywords: semiotics; passions; emotional dimension; modality; tensivity.

Recebido em: 11 de abril de 2016.

Aprovado em: 10 de agosto de 2016.

\section{Dos estados de coisas aos estados de alma: o nascimento de uma semiótica das paixões}

Tendo surgido em meio às discussões de cunho estruturalista da década de 60, a semiótica de linha francesa, preocupada em compreender os modos de produção da significação dos textos, procurou firmar-se enquanto uma teoria geral das ciências da linguagem, com metodologia eficaz e coerente. Iniciou seus estudos rejeitando, então, tudo aquilo que de perto ou de longe parecesse estar ligado a subjetivismos, e concentrou toda a sua atenção na depreensão das operações lógicas que estruturam os discursos. Assim, quando o interesse pelas paixões, ou, mais especificamente, pela dimensão passional dos enunciados surgiu no quadro geral da teoria, os semioticistas atentaram à necessidade de evitar uma tomada de posição ontológica, de afastar qualquer possibilidade de análise de natureza metafísica, ou de cunho psicológico, buscando, ao contrário, estabelecer conceitos operatórios passíveis de ser usados na descrição sintáxica dos núcleos passionais discursivizados, considerados modelos de previsibilidade, sistemas conotativos de reconhecimento das interações passionais já moldadas pelo uso.

O estudo das paixões no domínio da semiótica discursiva tem seu início em 1978, com a publicação do Bulletin 6, intitulado "Pour 
une théorie des passions", que anunciava as primeiras hipóteses de trabalho. Dois anos do Seminário de Semiótica geral de Paris (19781979 e 1979-1980) foram dedicados a pesquisas exploratórias e à busca de um método de descrição geral e abstrato, isento de considerações ideológicas e psicologizantes. Depois do exame sistemático das teorias propostas pelos filósofos, para o estudo das paixões, constatando que em meio a algumas diferenças todas elas tinham como traço comum a classificação de base taxionômica, a semiótica procurou trabalhar na direção de uma descrição sintáxica das paixões-lexemas, por meio das modalidades. Interessava aos semioticistas depreender e descrever a organização interna dos afetos, o seu modo de estruturação, e, para isso, os então recentes desenvolvimentos da teoria das modalidades pareciam bastante pertinentes.

Um dos textos mais representativos dessa época, que introduz a noção de timia relacionando-a à perspectiva modal, é "De la modalisation de l'être", publicado pela primeira vez em 1979 no Bulletin 7, e republicado anos mais tarde em Du sens II (1983). Nesse artigo, Greimas trabalha suas primeiras ideias para a depreensão de uma sintaxe modal própria ao ser do sujeito narrativo e à série de sub-articulações significantes da massa tímica amorfa, indício do primeiro contato interactancial, caracterizado primitivamente por atrações e/ou repulsões. Conforme explica Fontanille (2002, p. 603 $\left.{ }^{1}\right)$ :

Depois de ter consagrado os anos precedentes à modalização do "fazer", para estabelecer a competência modal do sujeito narrativo, Greimas aborda o que ele chama a existência modal do sujeito. A categoria das "modalidades do ser" (dever-ser, querer-ser, poder-ser, etc.) é definida em relação a uma categoria mais profunda, a "foria" (literalmente: o que leva em direção a...). [...] É assim que os dois

\footnotetext{
${ }^{1}$ Trecho original: "Après avoir consacré les années qui précèdent à la modalisation du 'faire', pour établir la compétence modale du sujet narratif, Greimas aborde ce qu'il appelle alors l'existence modale du sujet. La catégorie des 'modalités de l'être' (devoir-être, vouloir-être, pouvoir-être, etc.) est défine par rapport à une catégorie plus profonde, la 'phorie' (littéralement: ce qui porte vers...). [...] C'est ainsi que les deux pôles de la phorie, l'euphorie et la dysphorie, seront convertis respectivement, et plus précisément, en 'désirable / indésirable' (/vouloir-être/), en 'indispensable / nuisible' (/devoir-être/), en 'possible / impossible' (/pouvoir-être/), etc...”
} 
pólos da foria, a euforia e a disforia, serão convertidos respectivamente, e mais precisamente, em "desejável/ indesejável" (/querer-ser/), em "indispensável/ nocivo" (/dever-ser/), em “possível/impossível” (/ poder-ser/), etc...

O objetivo era estabelecer um equilíbrio entre o desenvolvimento dos estudos relativos à modalização do fazer e os da modalização do ser, dos modos de existência semiótica do sujeito a partir de sua relação com o objeto-valor. Isso interessava porque a teoria das modalidades estava no centro da intenção dos semioticistas de dar às paixões uma definição sintáxica, segundo deixa entrever a observação de Greimas (1978, p. $\left.4^{2}\right)$ :

No final das contas, talvez não seja inútil insistir sobre uma evidência: a reflexão a respeito da semiótica das paixões deve ser levada paralelamente a um exame mais aprofundado da teoria das modalidades. Nossa tentativa nesse domínio (Langages, 43, 1976) constitui apenas um ponto de partida. A determinação do estatuto e do comportamento das modalidades convertidas e inscritas nas estruturas semionarrativas de superfície, o estabelecimento de sequências modais canônicas, constitutivas da competência dos sujeitos, a descrição do procedimento de conversão das modalidades-predicados em valores modais, condição de sua axiologização, parecem-nos tarefas urgentes.

Os anos seguintes foram, dessa forma, consagrados ao aperfeiçoamento da teoria modal. Era preciso não apenas identificar combinações modais nos afetos, mas sobretudo compreender os diferentes

\footnotetext{
${ }^{2}$ Trecho original: "En fin de compte, il n'est peut-être pas inutile d'insister sur une évidence: la réflexion sur la sémiotique des passions doit être menée de pair avec un examen plus approfondi de la théorie des modalités. Notre première tentative dans ce domaine (Langages, 43, 1976) n'en constitue qu'un point de départ. La détermination du statut et du comportement des modalités converties et inscrites dans les structures sémio-narratives de surface, l'établissement des suites modales canoniques, constitutives de la compétence des sujets, la description de la procédure de conversion des modalitésprédicats en valeurs modales, condition de leur axiologisation, nous paraissent comme des tâches urgentes.
} 
modos de articulação entre elas, o agenciamento sintáxico muitas vezes incompatível, contraditório e paradoxal, bem como o funcionamento da dinâmica de conversão que dá a um arranjo de modalidades efeitos passionais. O grande desafio era, como coloca Fontanille em seu artigo de 1986, intitulado "Le tumulte modal: de la macro-syntaxe à la micro-syntaxe passionnelle", compreender o que se passa entre as modalidades, o dinamismo interno dos estados, de maneira que fosse possível estabelecer uma sintaxe de caráter intermodal. Isso explica a entrada do domínio da aspectualização nas pesquisas referentes ao exame dos núcleos passionais.

Nessa época de busca por maior compreensão do funcionamento das estruturas patêmicas, diversas investigações em torno de paixões tomaram lugar, seja a partir do ponto de vista dos lexemas-paixões, ou dos sintagmas narrativos realizados a partir de textos literários - a admiração (Thürlemann, 1980), o desespero (Fontanille, 1980), a cólera (Greimas, 1981), a indiferença (Marsciani, 1984), a nostalgia (Greimas, 1986), entre outros -, e ainda alguns poucos que já se aventuravam na representação das paixões a partir de estratégias discursivas da enunciação - Bertrand (1986, 2003) e Hénault (1986, 1994). Todas as análises, quaisquer que fossem seus pontos de vista, buscavam explorar as hipóteses da gramática narrativa e em especial os elementos levantados quando do estudo da manipulação, da ação, da sanção, e também da problemática da persuasão.

Entre essas publicações encontra-se ainda a proposição de Herman Parret (1982 e 1986) para uma tipologia morfológica das paixões - a partir de princípios de concatenação modal subjacentes às taxionomias fornecidas pelas línguas naturais -, muito criticada por se apresentar como apenas uma tradução semiótica do que já havia sido feito pelos filósofos (MARSCIANI, 1982). Como explica Fontanille (2002, p. 606³):

Greimas se esforçava para escapar, a qualquer custo, da tipologia das paixões e demonstrar a originalidade da abordagem semiótica em relação à tradição

\footnotetext{
${ }^{3}$ Trecho original: “Greimas s'efforçait à tout prix d'échapper à la typologie des passions, et de démontrer l'originalité d'une approche sémiotique pas rapport à la tradition philosophique, qui est presque systématiquement taxinomique en cette matière; la sémiotique des passions devait être une syntaxe, et l'analyse modale, notamment telle la pratiquait $\mathrm{H}$. Parret, en vrai philosophe, ramenait en partie la sémiotique des passions vers la taxinomie."
} 
filosófica, que é sistematicamente taxionômica nesta matéria; a semiótica das paixões devia ser uma sintaxe, e a análise modal, principalmente como a praticava $\mathrm{H}$. Parret, verdadeiro filósofo que é, reconduzia parcialmente a semiótica das paixões em direção à taxionomia.

O estudo das paixões, e o objetivo de uma descrição sintáxica desse novo universo de significação, sobretudo no que diz respeito à compreensão do funcionamento da estrutura subjacente, foi pouco a pouco trazendo à cena a problemática do sensível na sua articulação com o inteligível. O avanço das pesquisas no domínio do passional e a busca constante de aperfeiçoamento da proposição semiótica para a criação de um modelo geral de análise das paixões assinalaram a participação do sentir, mesmo que os semioticistas não soubessem ainda o melhor modo de tratar a questão, no processo de significação. Não só a noção de sujeito, na sua estrita relação actancial com o objeto, ganha mais espaço dentro da teoria, mas também a de corpo - enquanto elemento de mediação proprioceptiva (percepção do corpo-próprio) para a homogeneização semiótica entre a apreensão extero- (percepção do mundo exterior) e interoceptiva (percepção do mundo interior) - e, consequentemente, a de percepção. De acordo com Fontanille (PORTELA, 2006, p. 166 ${ }^{4}$ ):

O final dos anos 1980, uma vez colocada a teoria das modalidades, que faz a transição entre a semiótica narrativa e a do discurso, o seminário sobre as paixões, a virada "sensível" das pesquisas semióticas, a ascensão das abordagens fenomenológicas, é o momento em que nasce a semiótica que se faz hoje.

São duas as publicações de maior representação, e repercussão, dessa "virada rumo ao sensível" na qual embarca a semiótica, escritas quase que paralelamente: De l'imperfection (1987), de Greimas, e

\footnotetext{
${ }^{4}$ Trecho original: "La fin des années 80 , une fois posée la théorie des modalités, qui faisait la transition entre la sémiotique du récit et celle du discours, c'est d'abord le séminaire sur les passions, le virage « sensible» des recherches sémiotiques, la montée en puissance des approches phénoménologiques, c'est le moment où prend naissance la sémiotique qui se fait aujourd'hui".
} 
Sémiotique des passions (1991), de Greimas e Fontanille - traduzidos no Brasil em 2002 e 1993, respectivamente.

Em Da imperfeição (2002), Greimas, tendo ainda como base metodológica a teoria das modalidades, apresenta uma discussão sobre os modos de se apropriar da investigação relacionada à produção da significação na experiência estética a partir da articulação entre o inteligível e o sensível, lançando o conceito de estesia, referente à apreensão, à emoção estética que funde o sujeito da percepção ao objeto percebido. São os primeiros indícios da reflexão a respeito da emergência do sentido, das condições elementares de sua aparição, mais amplamente trabalhada em Semiótica das paixões (1993). Conforme aponta Lucia Teixeira (2002, p. 260), "é também com Da Imperfeição que o campo do sensível retorna fortemente às preocupações dos semioticistas, não só como busca metafórica de fontes fenomenológicas, mas também como apelo à entrada do corpo sensível no universo da produção do sentido". Alguns poucos anos depois, o livro Sémiotique des passions (1991) aparece com o objetivo de "balanço" dos resultados de pesquisa adquiridos até então. De acordo com Fontanille (2012), tratava-se da concepção de um projeto de síntese das aquisições e de perspectiva teórica.

Mesmo não sendo essa a intenção, essa obra marca uma grande mudança nos rumos da teoria, uma vez que a tentativa de esclarecer e estabelecer os princípios epistemológicos da semiótica das paixões trazia a necessidade de explicar de maneira coerente a geração das modalidades responsáveis pela descrição sintáxica dos afetos; ou seja, era preciso não apenas explicitar as condições estruturais dos núcleos patêmicos, mas também as pré-condições de configuração dessas unidades formais. Como explica Fontanille (1993a, p. 1575): “[...] tornava-se inevitável recorrer a uma reformulação epistemológica de todo o edíficio teórico (ao invés de construir um outro edifício ao lado), mostrando como a semiótica podia dar conta da nova problemática e, ao mesmo tempo, avaliando o custo teórico da operação".

\footnotetext{
${ }^{5}$ Trecho original: “[...] il devinait inévitable de procéder à une réfondation épistémologique de l'édifice tout entier (au lieu de bâtir un autre édifíce à côté), en montrant comment la sémiotique pouvait rendre compte de la nouvelle problématique et en évaluant le coût théorique de l'opération."
} 
A partir de então, a preocupação dos semioticistas vai se voltar completamente às questões ligadas mais propriamente ao sensível, à participação do corpo-próprio, da percepção, na geração da significação. Assim, mais do que os estudos apresentados desde o início do interesse da semiótica pelos afetos, é a discussão contida no último livro individual de Greimas, Da imperfeição, e nos capítulos inicias de Semiótica das paixões a responsável pela guinada da teoria rumo ao sensível. Contudo, se a problemática é levantada, sendo substancialmente apresentada sobretudo nas páginas introdutórias de Semiótica das paixões - que custou aos autores, segundo Fontanille (1993a, p. 1576), "dois anos inteiros de discussões, escrita e reescritas sucessivas" -, ela não aparece da mesma forma nas análises contidas nos capítulos seguintes do livro. De acordo com Landowski (2005, p. 98):

$[\ldots]$ esquecendo aparentemente as promessas da introdução e do capítulo inicial, [os autores] voltam a um estágio metodológico e teórico anterior, aquele da gramática narrativa dos anos 1970-80. Suas descrições desenvolvem-se quase que de modo integral no terreno modal, o que os conduz a privilegiar a tal ponto a dimensão do conhecer, o "cognitivo" em detrimento do "sensitivo", que finalmente a questão das formas da coabitação esperada entre essas duas dimensões não será retomada.

Nesse sentido, o sensível encontra espaço no quadro teórico da semiótica das paixões, mas o mesmo não acontece com o lugar que deveria ocupar também na metodologia concebida para o estudo dos afetos, pois o modelo de análise consagrado a partir desta publicação, como veremos a seguir, é o esquema passional canônico, no qual o exame das modulações, responsáveis pelo estabelecimento da estrutura modal no nível narrativo, não está previsto. O próprio Greimas parecia ter ciência disso, conforme lembra Fontanille (PORTELA, 2006, p. 1697): "ele me confidenciou um dia, comentando o subtítulo de Semiótica das paixões,

\footnotetext{
${ }^{6}$ Trecho original: “[...] deux années entières de discussions, d'écriture et réécritures successives."

${ }^{7}$ Trecho original: "Il m'a confié un jour, en commentant le sous-titre de Sémiotique des passions, "Des états de choses aux états d'âme ", que dans ce livre, il estimait que nous avions «manqué les états d'âme"."
} 
'dos estados de coisas aos estados de alma', que nesse livro, ele avaliava que nós tínhamos 'ficado devendo' aos estados de alma”.

É bem verdade que nessa época a questão do sensível era ainda bastante frágil e mesmo hipotética, demandando estudos e desenvolvimentos mais detalhados, só apresentados posteriormente. Era preciso compreender "como articular o contínuo? Como tratar de modo imanente a energia e a intensidade? Como tratar de maneira coerente aquilo que parece irredutivelmente heterogêno? etc" (FONTANILLE, 1993a, p. $157^{8}$ ).

A inserção da problemática do sensível, ao impor, então, uma revisão dos princípios epistemológicos antes estabelecidos, acaba por elevar a afetividade ao estatuto de dimensão da atividade de linguagem, e, a partir daí, ela começa a interessar, e a ser pensada, enquanto componente geral da significação. Nas palavras de Fontanille (1995, p. 1869):

Tudo se passa como se uma outra racionalidade reclamasse seus direitos, e mais ainda quando as manifestações do corpo-próprio (a proprioceptividade, na terminologia semiótica) se impõem ao discurso modificando o seu curso; é como uma outra dimensão do sujeito que se fixa, e não mais somente aquela que é requerida para a realização de programas narrativos, mas sobretudo aquela na qual se afirma sua identidade de sujeito e seu sentido de ser.

Essa nova direção das pesquisas marca a "virada fenomenológica" da disciplina, e faz com que os semioticistas passem a se interessar cada vez mais pela questão da significação em ato, do devir, da emergência do sentido. É aí que as noções de percepção, presença e tensividade vão ganhando mais força e relevância no quadro geral da teoria. Como

\footnotetext{
${ }^{8}$ Trecho original: "[...] comment articuler le continu? comment traiter en immanence l'énergie et l'intensité? comment traiter de manière isotope ce qui semble irréductiblement hétérogène? etc."

9 Trecho original: "Tout se passe comme si une autre rationalité réclamait ses droits, et plus encore quand les manifestations du corps propre (la proprioceptivité, dans la terminologie sémiotique) s'imposent au discours et en modifient le cours; c'est alors une autre dimension du sujet qui s'affiche, non plus celle, seulement, qui est requise pour la réalisation des programmes narratifs, mais celle, plutôt, où s'affirme son identité de sujet et son sens d'être."
} 
explica Beividas (2011, p. 19), "tendo o sensível ganhado paulatinamente a primazia no concurso da emergência da significação, o afeto passa de efeito à 'razão' das razões do sentido".

De todo modo, se os estudos no campo do sensível, ou da afetividade enquanto dimensão, evoluíram e continuam em pleno desenvolvimento, o exame propriamente dos estados de alma não progrediu da mesma maneira. A metodologia oferecida e consagrada à análise semiótica das paixões permanece conforme ao esquema passional canônico, no qual a ênfase é dada à estrutura modal, enquanto o sensível e as noções daí advindas continuam a não encontrar o seu lugar. A investigação semiótica sobre a configuração dos afetos, mesmo reconhecendo as indicações e especificidades desse outro universo de significação, da ordem do sensível, que desde o início apontou para a necessidade de transpor a abordagem descontínua do sentido, integrando os aspectos contínuos próprios à articulação entre inteligível e sensível, como foi discutido na introdução de Semiótica das paixões (1993), continuou, pois, fundamentada sobretudo nas modalidades, responsáveis por instituir, reciprocamente, o estatuto do sujeito e do objeto.

Assim, a análise semiótica das paixões, na maioria das vezes, faz-se ainda hoje quase exclusivamente em termos de sintaxe modal, isto é, de dispositivos e combinações de modalidades que estruturam o estado do sujeito narrativo. O passional, no entanto, como apontam os próprios autores de Semiótica das paixões (GREIMAS; FONTANILLE, 1993), logo no início da obra, não é apenas uma organização sintagmática e modal, mas deve ser considerado também sobre o fundo de uma problemática tensiva e sensível, inerente à determinação fórica, tal como será proposto anos depois, por Fontanille e Zilberberg, em Tensão e significação $\left(2001^{10}\right)$.

Em seu debate com Paul Ricoeur, em 1989, a propósito da semiótica das paixões, Greimas admite (HÉNAULT, 1994, p. 203"11): “[...] somos forçados, depois de muita hesitação (porque uma vez estabelecidos os princípios teóricos nós temos vontade de parar por aí), a reconhecer

\footnotetext{
${ }^{10}$ A publicação do original surge na França em 1998.

${ }^{11}$ Trecho original: “[...] on est forcé après moult hésitations (parce qu'une fois qu'on a établi des principes théoriques qui paraissent satisfaisants on a envie de s'y tenir), on est forcé de reconnaître que le discours, ça bouge, qu'il y a des forces qui ne s'expliquent pas entièrement par les modalités, qu'il y a autre chose."
} 
que o discurso se movimenta, que ele tem forças que não se explicam inteiramente pelas modalidades, que há algo mais".

A combinação modal ocupa, sem dúvida, um papel fundamental no estudo das paixões, porque define a identidade, o ser do sujeito narrativo e o conflito que caracteriza seus "estados de alma"; ela torna possível a depreensão das fases da manifestação afetiva enunciada e o seu papel na produção de uma dada paixão. As modalidades estão no centro da estrutura de configuração dos afetos, "traduzindo" a interação estabelecida entre sujeito apaixonado e objeto da paixão; mas sozinhas, elas nada dizem a respeito do "excesso" propriamente dito, das modulações tensivas que subjazem às articulações modais e sensibilizam a interação, o esquema narrativo como um todo. Conforme salientam Greimas e Fontanille (1993, p. 21):

Uma primeira constatação impõe-se: a sensibilização passional do discurso e sua modalização narrativa são co-ocorrentes, não se compreendem uma sem a outra, e, no entanto, são autônomas, submetidas, provavelmente, ao menos em parte, a lógicas diferentes.

Mesmo ao explorar a dimensão patêmica dos textos, a investigação sobre os elementos constitutivos de uma dada paixão, quando presa unicamente à estrutura modal, fica limitada aos conteúdos inteligíveis da configuração, porque as modalidades, colocadas como peças-chave da análise, dizem respeito ao encadeamento sintáxico dos dispositivos atuantes no nível narrativo, não podendo ajudar no exame do componente propriamente sensível que o engendra. Os autores advertem (Idem, p. 68): "os efeitos de sentido passionais não podem encontrar explicação satisfatória apenas no seio do nível semionarrativo", e explicam: "os dispositivos modais pertencem de direito ao semionarrativo; constituem 'realizáveis' do esquema semiótico, mas as paixões que deles se nutrem constituem-se de fato no seio no nível discursivo" (Idem, p. 69). Os semioticistas acrescentam ainda (Idem, p. 90):

Elaborar uma semiótica das paixões é, portanto, tomar o partido de uma representação da dimensão narrativa dos discursos que não se reduz a uma espécie de lógica da ação nem a uma concepção do 
sujeito que seria inteiramente determinado por seu fazer e pelas condições necessárias para realizá-lo.

Para que se possa, pois, compreender a estruturação discursiva da paixão, é preciso atentar tanto à articulação modal quanto ao aspecto propriamente sensível da configuração patêmica, das modulações tensivofóricas responsáveis pela sensibilização das modalidades em questão, indo além da ideia (ou da pressuposição lógica) de um "excedente modal", de uma intensidade subjacente. De grande importância à análise dos afetos, a observação relativa à foria - entendida como aspectualização no nível discursivo e como modulação tensiva no nível profundo - propicia o exame do desenvolvimento contínuo e progressivo do núcleo passional, ou seja, das modulações articuladas à direção tensiva que conduz e controla o encaminhamento discursivo, uma vez que a dimensão fórica perpassa todo o percurso gerativo, configurando o elemento sensível junto ao processo discursivo. A esse propósito, Fontanille (2007, p. 184) explica:

[...] a teoria das modalidades foi o primeiro passo na direção de uma semiótica das paixões: os efeitos passionais, graças ao componente modal oriundo da narratividade, tornam-se analisáveis, cada efeito passional podendo ser reduzido, de um ponto de vista narrativo, a uma combinação de modalidades. Portanto, os afetos passionais eram considerados como simples epifenômenos do percurso narrativo dos actantes. Todavia essa abordagem do domínio afetivo permanecia nos limites de uma lógica das transformações, a lógica do discurso-enunciado. Fica bem claro, no entanto, que a dimensão afetiva do discurso não pode ser privada da presença, da sensibilidade e do corpo que toma posição na instância do discurso, pois a afetividade reivindica o corpo do qual ela emana e o qual ela modifica.

A problemática do sensível, como se pode entrever, não é apenas uma questão de nível de pertinência, pois ela atravessa de uma ponta a outra a geração da configuração passional, estando intrinsecamente ligada às condições de sua estruturação. São as operações subjacentes às modalidades, do domínio das modulações, que as predispõem a 
participar das configurações patêmicas reconhecíveis em determinada cultura. Como admite Fontanille (1993a, p. 157'12), "[...] anteriormente a sua discretização sob a forma de determinações do nível semio-narrativo, as modalidades são variações calculáveis no seio do espaço tensivo".

$\mathrm{O}$ exame das modulações, dessa forma, diretamente ligado ao devir da interação passional, a partir da inserção dos valores no campo de presença do sujeito, refina e aprofunda o estudo dos afetos em semiótica, podendo, então, ultrapassar os limites do discurso-enunciado e examinar a configuração passional no momento de sua emergência, no domínio da significação em ato, da articulação entre o sensível e o inteligível.

É por isso que, de nossa parte, retomando: (i) a discussão apresentada nas páginas introdutórias de Semiótica das paixões ${ }^{13}$ (1993), (ii) reexaminada em Tensão e significação (FONTANILLE; ZILBERBERG, 2001), quando ela ganha um tratamento mais formal, (iii) e em diversos outros textos de Fontanille e Zilberberg, pretendemos propor a reformulação do esquema passional canônico a partir de um ponto de vista tensivo, de modo que o modelo de análise semiótica das paixões evolua par a par com os desenvolvimentos atuais da teoria. A ideia é apresentar uma (re)formulação metodológica da teoria já esboçada na introdução de Semiótica das paixões (1993), desta vez, com a percepção ocupando o papel de "pedra angular" na produção dos afetos.

Além do exame das características da dimensão passional nos níveis narrativo e discursivo, a ideia é que o modelo de análise proposto dê conta também das condições de geração destas especificidades, da base tensivo-fórica subjacente, concebendo a paixão como resultado de correlações ao mesmo tempo sensíveis e inteligíveis. Dessa forma, em nossa proposta, a paixão será entendida, antes de mais nada, como resultante de um determinado modo de interação afetiva, caracterizado a partir de peculiaridades próprias à experiência (perceptiva) entre o sujeito da percepção e o objeto percebido. Trata-se da apresentação de uma semiótica das paixões fundamentada nas estruturas elementares da

\footnotetext{
12 Trecho original: “[...] antérieurement à leur discrétisation sous la forme de déterminations du niveau sémio-narratif, les modalités sont des variations calculables au sein d'un espace tensif."

${ }^{13}$ Estamos nos referindo aqui tanto ao conteúdo da "Introdução", quanto do capítulo 1, intitulado "A epistemologia das paixões".
} 
significação, com o sujeito do afeto constituindo-se como um algoritmo da percepção (DISCINI, 2011).

Um exame das paixões que leve em conta o componente propriamente sensível, na sua articulação com o inteligível, parece válido por permitir concebê-las na própria emergência passional da relação intersubjetiva, depreendendo, para além das características de um perfil, as condições enunciativas - de produção e de captação do acontecimento passional, bem como uma maior compreensão das especificidades de instauração dos diferentes modos de interação afetiva entre o sujeito e aquilo que se põe em seu campo de presença, do(s) elemento(s) responsável(is) pelas distintas formas de reação afetiva ao contato com o outro.

\section{0 esquema passional canônico e o seu aperfeiçoamento}

Greimas e Fontanille, a partir dos estudos realizados em Semiótica das paixões (1993), procurando instituir uma coerência formal ao percurso passional do sujeito apaixonado, fixaram, a exemplo do tradicional esquema narrativo canônico [manipulação - competência - performance - sanção], o esquema passional canônico [constituição - sensibilização (disposição - patemização - emoção) - moralização], considerado, tal como o primeiro, um modelo autônomo e dotado de um valor heurístico próprio.

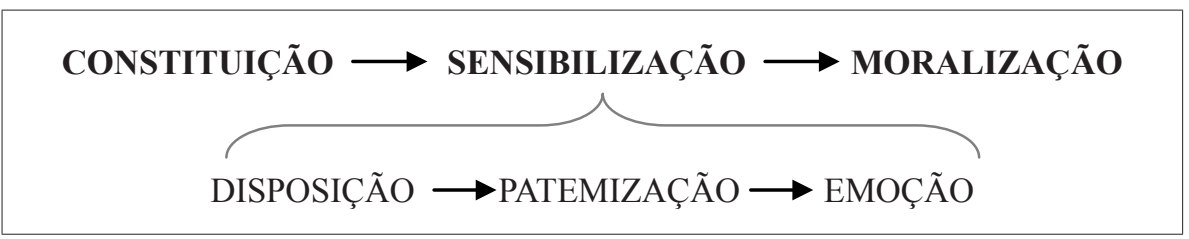

Esquema 1: Esquema passional canônico sugerido em Semiótica das paixões (GREIMAS; FONTANILLE, 1993).

A ideia era o estabelecimento de um modelo de análise "concebido e construído como estrutura generalizável" (GREIMAS; FONTANILLE, 1993, p. 61), isento, na medida do possível, do relativismo cultural, permitindo que as configurações passionais dos discursos pudessem ser identificadas e descritas independentemente de sua lexicalização. Assim, a estratégia de concepção do esquema é a de fases agenciadas 
progressivamente, ordenando de maneira dedutiva e calculável o desenvolvimento do percurso patêmico que afeta o sujeito narrativo.

A constituição, a sensibilização e a moralização foram, pois, reconhecidas como as três principais formas de construção dos universos passionais que controlam as culturas individuais e as coletivas. Segundo os autores (1993, p. 244-245), "esses três segmentos comportam, no esquema patêmico canônico, referências às axiologias passionais, e, mais particularmente, àquelas que asseguram a regulação das relações sociais interindividuais". Eles acrescentam (Idem, p. 245): "[os três segmentos] convocam para isso grades idioletais e socioletais de representação da paixão, de suas causas, de seus efeitos, de seus critérios de identificação e de avaliação". Dentro desse quadro, a disposição, a patemização e a emoção correspondem às etapas sucessivas do processo passional propriamente dito (sensibilização), do momento juntivo que marca a relação entre o sujeito e o seu objeto tímico.

Dois anos após a publicação original de Sémiotique des passions (1991), Fontanille, em um artigo intitulado "Le schéma des passions", de 1993b - revista Protée, volume 21, número 1 -, apresenta o que ele chama de "uma reformulação, explicação e ilustração das proposições feitas hipoteticamente sobre este assunto em Semiótica das paixões" ( $\mathrm{p}$. $33^{14}$ ). Nesse texto, ao contrário do que foi apresentado na primeira vez, o semioticista busca não apenas elucidar as etapas do modelo (agora esquematizado sem subdivisões: constituição - disposição-patemização - emoção - moralização), mas também incluir um ponto de vista mais próximo à noção de tensividade, cujo valor operatório é discutido na Introdução que antecede os capítulos de análise do livro escrito em parceria com Greimas.

De acordo com o autor (1993b, p. 33'5), "o esquema patêmico proposto em Semiótica das paixões resulta, no plano epistemológico, tanto de uma generalização, a partir de um conjunto de considerações

\footnotetext{
${ }^{14}$ Trecho original: "Cette présentation du schéma pathémique canonique se présente tout d'abord comme une reformulation, une explication et une illustration des propositions faites sur ce sujet, à titre d'hypothèse, dans Sémiotique des passions."

${ }^{15}$ Trecho original: "Le schéma pathémique proposé dans Sémiotique des passions résulte, au plan méthodologique, à la fois d'une généralisation à partir d'un ensemble de considérations pratiques, et d'une extrapolation à partir du schéma narratif canonique."
} 
práticas, quanto de uma extrapolação do esquema narrativo canônico". Mas ele adverte (p. 34+6):

[...] o método que dirige a elaboração dos dois esquemas é muito diferente: o ENC [esquema narrativo canônico] resulta da 'bricolage', da redução de um conjunto de 'funções' proppianas e de noções emprestadas da linguística chomskiana, bricolagem e redução com o intuito de integrar mutuamente a reflexão sobre a lógica narrativa e a reflexão sobre os diversos modos de existência dos fatos linguísticos; [...] o EPC [esquema passional canônico] resulta de um tateamento, de uma elaboração progressiva motivada por um único objetivo: detalhar as operações constitutivas do processo passional, a partir das primeiras análises concretas realizadas sobre essa questão durante toda uma década, dandolhes, de maneira homogênea, nomes de operações (o que explica o sufixo "-ção").

De qualquer forma, com base no esquema narrativo, o esquema passional canônico - tanto em Semiótica das paixões, quando a tensividade ainda aparecia nas análises práticas de modo bastante tímido, quase somente em termos de aspectualização, quanto neste texto posterior de Fontanille, no qual o autor procura apresentá-la de forma mais evidente - acabou privilegiando não o exame e a descrição das peculiaridades sintáxicas da configuração patêmica em si, ou, como diz o próprio autor, "as operações constitutivas do processo passional", mas os diferentes estados passionais no percurso patêmico do sujeito apaixonado nos discursos.

\footnotetext{
${ }^{16}$ Trecho original: “[...] la méthode qui a présidé à l'élaboration des deux schémas est très différente: le SNC résulte du 'bricolage' et de la réduction d'un ensemble de 'fonctions' proppiennes et de notions empruntées à la linguistique chomskienne, bricolage et réduction de nature à intégrer l'une à l'autre la réflexion sur la logique narrative et la réflexion sur les divers modes d'existence des faits linguistiques; [...] le SPC résulte d'un tâtonnement, d'une élaboration progressive motivée par un seul objectif: détailler les opérations constitutives du processus passionnel, à partir des premières analyses concrètes menées sur cette question pendant une dizaine d'années, et leur donner de manière homogène des noms d'opérations (d'où le suffixe 'tion')."
} 
As etapas da sequência estabelecida no esquema passional canônico definem, portanto, estágios de evolução do estado patêmico do sujeito, ou seja, identidades transitórias do sujeito discursivo no sintagma passional, papéis patêmicos que permitem a compreensão de seu estilo global, sua identidade afetiva a partir da junção; isso porque a ideia era representar "sob a forma de um esquema canônico os diversos modos de existência do sujeito apaixonado" (FONTANILLE, 1993b, p. $35^{17}$ ). Em função disso, a configuração propriamente dita do processo patêmico, as condições de emergência, de articulação do sensível com o inteligível na produção da afetividade, ficaram de fora, com as paixões sendo identificadas e descritas a partir de comportamentos estereotipados traduzidos em modalidades, sem a possibilidade de explicar também as modulações tensivas que fazem de tais combinações modais estruturas passionais, bem como as particularidades sintáxicas subjacentes aos patemas-processos concebidos como "conjunto das condições discursivas necessário à manifestação de uma paixão-efeito de sentido" (GREIMAS; FONTANILLE, 1993, p. 78).

Nessa primeira proposição do esquema passional canônico, Greimas e Fontanille (1993) definem a etapa da constituição como sendo um determinismo do sujeito: social, psicológico, hereditário, ou qualquer outro, mas sempre anterior a toda competência e disposição, típicas à instauração do sujeito apaixonado. Trata-se, como aparece na ocasião do estudo do ciúme, do momento em que é engendrado "o estilo tensivo do sujeito apaixonado" (GREIMAS; FONTANILLE, 1993, p. 243). É esta última concepção que defenderá Fontanille no artigo de 1993b, quando ele apresenta a constituição como a "etapa durante a qual o sujeito patêmico emerge no discurso [...] essencialmente por sua receptividade a todas as solicitações passionais procedentes de seu entorno" (p. $\left.35^{18}\right)$. Para o autor, nessa fase, agora reconhecida como sendo de modulações rítmicas (andamento) e quantitativas instáveis, o sujeito é apenas um sujeito que sente (FONTANILLE, 1993b).

\footnotetext{
${ }^{17}$ Trecho original: "[le SPC] traduit sous la forme d'un schéma canonique les divers modes d'existence du sujet passionné."

${ }^{18}$ Trecho original: "La 'constitution' est l'étape pendant laquelle le sujet pathémique émerge dans le discours [...] essentiellement par sa réceptivité à toutes les sollicitations passionnelles issues de son environnement."
} 
A sensibilização e a moralização, pensadas em Semiótica das paixões como gestos culturais pelos quais determinada cultura "interpreta uma parte dos dispositivos modais, concebíveis dedutivamente, como efeitos de sentidos passionais" (GREIMAS; FONTANILLE, 1993, p. 140), são consideradas, em ambos os textos, como instâncias culturais de reconhecimento, articuladas de modo próprio à emergência discursiva da configuração patêmica propriamente dita, segundo os códigos identificáveis já firmados pelo uso.

O estágio da sensibilização, articulado pelas fases da disposição, da patemização e da emoção, corresponde, dessa forma, à manifestação da paixão propriamente dita, passível de ser descrita, segundo coloca Fontanille (1993b), a partir (i) da articulação modal subjacente à identidade e à competência afetivas do sujeito, determinadas por sua relação com o objeto-valor (fase da disposição), (ii) da identificação de um comportamento estereotipado que, segundo as prescrições culturais, permite reconhecer e nomear o estado patêmico em questão (fase da patemização), e (iii) da expressão somática consequente (fase da emoção).

A propósito da moralização, como explicam Greimas e Fontanille (1993, p. 154), ela "intervém em fim de sequência e recai sobre o conjunto, mas mais particularmente no comportamento observável". É o momento da inserção da configuração passional no espaço de julgamento individual, ou coletivo, de certa comunidade. Em função do excesso, da insuficiência, ou da medida manifestados, a paixão é, nessa etapa, moralizada por um observador social.

O esquema passional canônico, em sua primeira e segunda versão, apresenta-se, então, da seguinte maneira (cf. Esquema 2): 


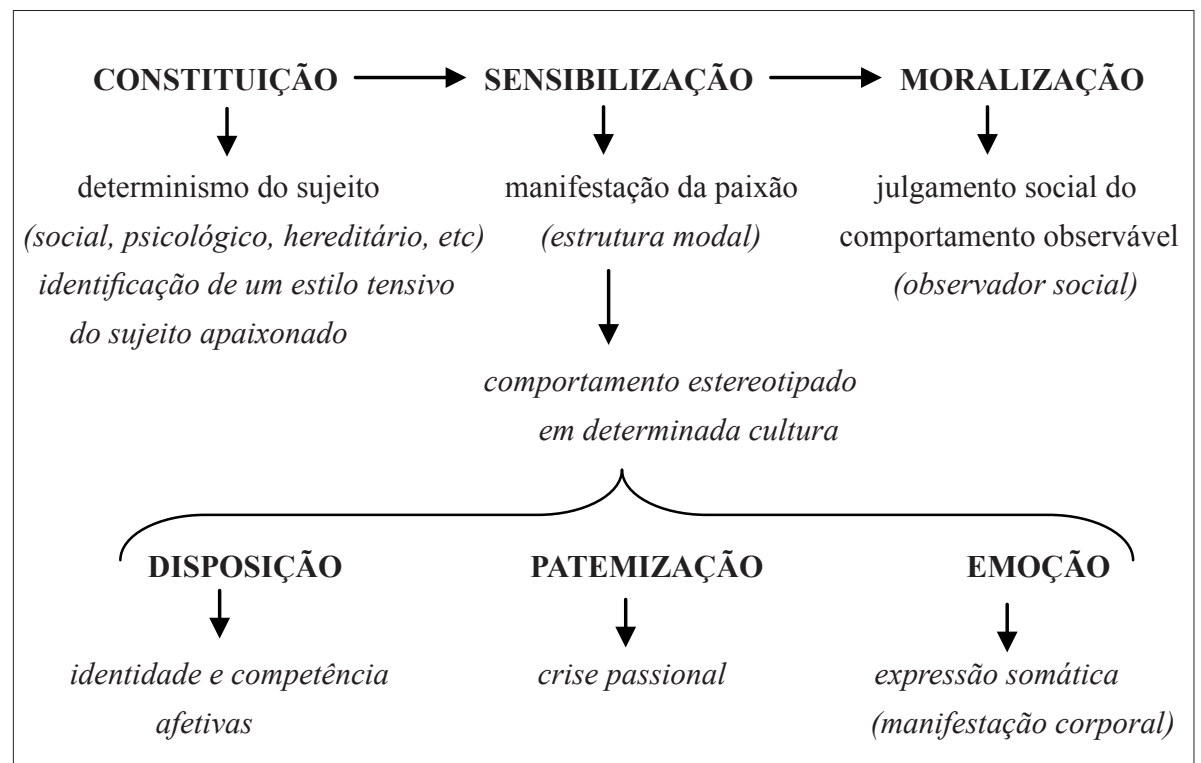

Esquema 2: Descrição das etapas do esquema passional canônico apresentadas em Semiótica das paixões (GREIMAS; FONTANILLE, 1993).

Em suma, mesmo na reformulação proposta por Fontanille (1993b), o papel da tensividade na configuração dos afetos, tão discutido na introdução do livro que oficializa o surgimento de uma semiótica das paixões, continua restrito à fase da constituição, como pré-condição da instauração do núcleo patêmico, sem muitas indicações sobre a maneira pela qual ela pode ser depreendida nos discursos, e sobre sua influência na determinação das fases seguintes. As "operações" sintáxicas subjacentes, responsáveis pelo surgimento dos estados de alma, das modalidades que traduzem a interação e a junção do sujeito com seu objeto tímico, permanecem também ofuscadas por estágios patêmicos já manifestados. É só na "remodelagem" apresentada em Sémiotique du discours (1998; 2003, $2^{\mathrm{a}}$ ed. ampliada), depois em Sémiotique et littérature (1999), e, anos mais tarde, no artigo "Sémiotique des passions", em Questions de sémiotique (HÉNAULT, 2002) - publicações, se não paralela, posteriores a Tension et signification, de 1998 -, que essas questões vão ser mais bem delineadas, passando da identificação de um percurso narrativo do sujeito apaixonado a uma sintaxe tensiva dos estados de alma. 
Nessa terceira reformulação do esquema passional canônico, embora o número de fases tenha sido mantido, com troca apenas de alguns dos nomes (despertar afetivo - disposição - pivô passional - emoção - moralização), Fontanille (1999) propõe a projeção de uma estrutura e de uma variação tensivas subjacentes a todas as etapas da sequência, descritas agora em termos de intensidade e extensidade, de movimentos de ascendência e de descendência, nos quais está prevista a ideia de presença. Trata-se da perspectiva já lançada em Tensão e significação (2001), no capítulo "Paixão", quando Fontanille e Zilberberg assinalam, a propósito da sintaxe da dimensão passional dos enunciados, a correlação entre a dimensão modal e a dimensão fórica, definidas em termos de constituintes (modais) e expoentes (tensivos), respectivamente.

Assim, a fase do despertar afetivo é entendida como o momento ascendente em que a sensibilidade do sujeito é despertada por uma presença caracterizada segundo sua intensidade e extensidade, que são, por sua vez, representadas por códigos rítmicos e aspectuais (expoentes tensivos). A disposição continua a ser considerada o estágio no qual "o sujeito recebe a identidade modal necessária para experimentar uma paixão ou um tipo de paixão e não uma outra" (FONTANILLE, 1999, p. $80^{19}$ ), como uma espécie de competência (modal) patêmica, classificada como descendente, por conta da colocação em cena de códigos modais (constituintes modais). O pivô passional também permanece como a principal etapa da sequência, na qual, através dos códigos figurativos, manifesta-se a paixão. Como explica Fontanille (2002, p. 63120), "essa fase é característica de um movimento de 'ascendência', pois ela põe em cena tanto um aumento da intensidade, quanto uma contração do campo de representações cognitivas, [...] na 'condensação' da extensidade e no 'deslocamento' (e a progressão) do acento de intensidade". $\mathrm{Na}$ emoção, manifestação corporal do sujeito afetado pelo impacto da fase anterior, "são, novamente, os expoentes tensivos que ocupam o primeiro plano, sobretudo a intensidade, por meio dos códigos

\footnotetext{
${ }^{19}$ Trecho original: “[...] le sujet reçoit l'identité modale nécessaire pour éprouver une passion ou un type de passion et pas un autre."

${ }^{20}$ Trecho original: 'Cette phase est caractéristique d'un mouvement d' 'ascendance', car elle se développe à la fois par une augmentation de l'intensité et une contraction du champ des représentations cognitives [...] à la fois sur la 'condensation' de l'étendue et sur le 'déplacement' (et la croissance) de l'accent d'intensité."
} 
somáticos" (FONTANILLE, 1999, p. 8121). A moralização, culturalmente determinada por seu caráter de avaliação e de "medida" das manifestações emocionais, do comportamento observável, é compreendida como uma fase de atenuação, de controle da paixão.

O esquema passional canônico passa, portanto, a se configurar do seguinte modo (cf. Esquema 3):

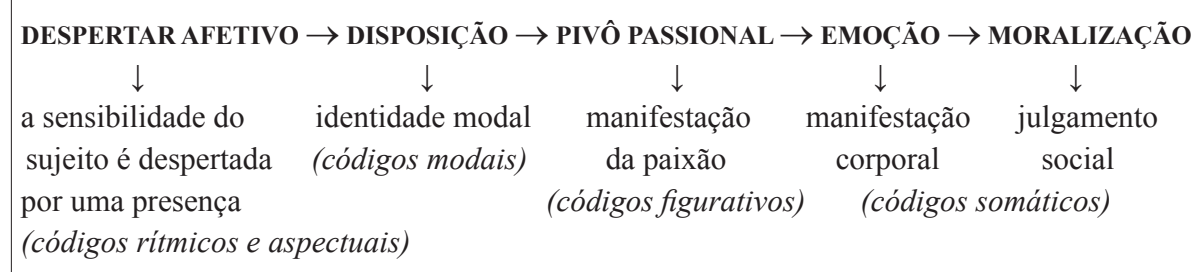

Esquema 3: Esquema passional canônico proposto por Fontanille (1999; 2000; 2002a).

Nesta última proposta do esquema, o exame das modulações tensivas é de fato trazido à cena, bem como as operações sintáxicas subjacentes aos patemas-processo, isto é, ao "conjunto das condições discursivas necessário à manifestação de uma paixão-efeito de sentido" (GREIMAS; FONTANILLE, 1993, p. 78). No entanto, a nosso ver, mais do que as condições de emergência dos afetos na relação do sujeito com o objeto-valor, o modelo de análise continua a privilegiar a identificação e descrição de estados de alma já configurados, com a dimensão passional examinada no âmbito do uso, do discurso enunciado.

É por isso que, ao entender a paixão como uma configuração cujas correlações, provenientes de diversos níveis do percurso gerativo, são ao mesmo tempo sensíveis e inteligíveis, propomos, como sugestão de atualização do esquema passional canônico, um modelo de análise fundamentado sobretudo nas especificidades de configuração da interação que faz emergir a paixão, o afeto, desta vez, na perspectiva da enunciação, da significação em ato, e não exatamente na descrição do percurso patêmico do sujeito no discurso enunciado, como feito até então.

\footnotetext{
${ }^{21}$ Trecho original: "Ce sont donc, à nouveau, les exposants tensifs qui reviennent au premier plan, notamment l'intensité, à travers les codes somatiques de l'émotion."
} 


\section{A interpretação tensiva do esquema passional canônico: uma proposta}

Segundo assinala Fontanille (2007, p. 213), "a racionalidade passional consiste em conjugar gradientes perceptivos, gradientes da presença perceptiva em discurso", isso porque, "segundo a perspectiva da paixão, um processo não é considerado do ponto de vista de seu resultado, mas do ponto de vista de seu peso de presença" (Idem, p. 213). $\mathrm{O}$ estado juntivo que determina a interação passional entre o sujeito e o objeto-valor, a existência semiótica, será considerado, pois, conforme apresentamos anteriormente, como uma relação, antes de mais nada, perceptiva, na qual prevalece a problemática das modulações e do devir passional.

Buscamos, desse modo, pensar as sequências do modelo proposto em Semiótica das paixões (1993) em um grau mais abstrato, com as modulações tensivas entendidas como propriedades elementares da percepção, como componentes do processo subjacente a determinado modo de interação afetiva, mais da ordem do sensível, ou mais da ordem do inteligível. A ideia é a de apresentar um estudo das paixões, dentro do quadro epistemológico da semiótica discursiva, assentado nas noções de percepção e de presença, conforme as entende a linha tensiva da teoria, sugerindo um percurso de análise capaz de dar conta das operações sintáxicas subjacentes à configuração das interações patêmicas, das suas condições de emergência.

Nessa nova interpretação do esquema, que privilegia a perspectiva da semiótica tensiva, a etapa da constituição passa a ser considerada como a da instauração do campo de presença. É, então, concebida como a fase na qual, a partir das primeiras somações resultantes da tensão criada na coexistência do sujeito e do "mundo natural" que se impõe a ele enquanto tensividade fórica, uma presença sensível se institui no campo de percepção do sujeito, dando origem à interação perceptiva.

Na sequência, a sensibilização responderia, então, pelo processo de assimilação da presença, a articulação do sensível com o inteligível na produção da interação patêmica que liga sujeito perceptivo e objetovalor percebido. É o estágio de categorização do sensível, de atuação da semiose. Agora é o sujeito que se impõe ao mundo enquanto ser dotado de linguagem. Em sua subdivisão, a disposição seria o estabelecimento das determinações tensivas, das modulações intensivas e extensivas 
que determinam a profundidade do campo de presença instaurado. A patemização será, por sua vez, o segmento sensibilizador por excelência, o momento no qual, através da convocação sensível-inteligível do sujeito da percepção, os acentos fóricos (valores virtuais), convertem-se em valores axiológicos. É a etapa na qual se engendra a competência do sujeito da percepção para sentir, para vivenciar esta ou aquela paixão. A emoção virá, dessa forma, como consequência. Ela diz respeito ao grau de impacto da tensão apreendida, à reação somática manifestada (somação) diante do modo de presença do objeto-valor para o qual a afetividade suscitada é dirigida. Ela poderá ser tônica ou átona, forte ou fraca, a depender das determinações tensivas configuradas na etapa da disposição. É o estágio em que se define o estilo tensivo da interação patêmica, a natureza qualitativa do liame interactancial. Se a interação estiver sendo dirigida pelo sensível, o sujeito "perderá o controle" e se fundirá ao objeto-valor do afeto; mas, se ao contrário, for o inteligível a dimensão preponderante na assimilação da presença, o sujeito manterá o controle da emoção, que se tornará mais "inteligibilizada".

A moralização, ao agir no fim do percurso de configuração, equivaleria, nessa nova proposta de leitura do esquema passional canônico, à resolução, ao grau de intersubjetividade convocado, prescrevendo o modo de interação afetiva que define a paixão, passível, nesta fase, de ser traduzida em termos de modalidades, de combinatórias modais. Trata-se da etapa na qual se consolida a conversão do valor axiológico apreendido em valor tímico, o "valor do valor", elemento central na configuração dos afetos. Quanto maior e mais forte for o impacto da presença do objeto-valor da afetividade, sentido pelo sujeito da percepção na etapa da emoção, mais tônica e sensível será a sanção intersubjetiva; por outro lado, quanto menor e mais fraca a presença, mais átona e inteligível a sanção se produzirá. A interação afetiva, na fase da moralização, tal como concebida nessa outra interpretação do esquema, configura-se para o próprio sujeito da percepção, independentemente da sanção de um observador social outro, que pode estar presente ou não, pode se dar conta ou não da relação intersubjetiva emergente. Trata-se, agora, da configuração da paixão para o próprio sujeito apaixonado e não mais a partir de um julgamento exterior do comportamento observável, conforme haviam formulado Greimas e Fontanille em Semiótica das paixões (1993). 
Em resumo (cf. Esquema 4), as etapas do esquema passional canônico a partir desse novo ponto de vista podem ser concebidas da seguinte forma:

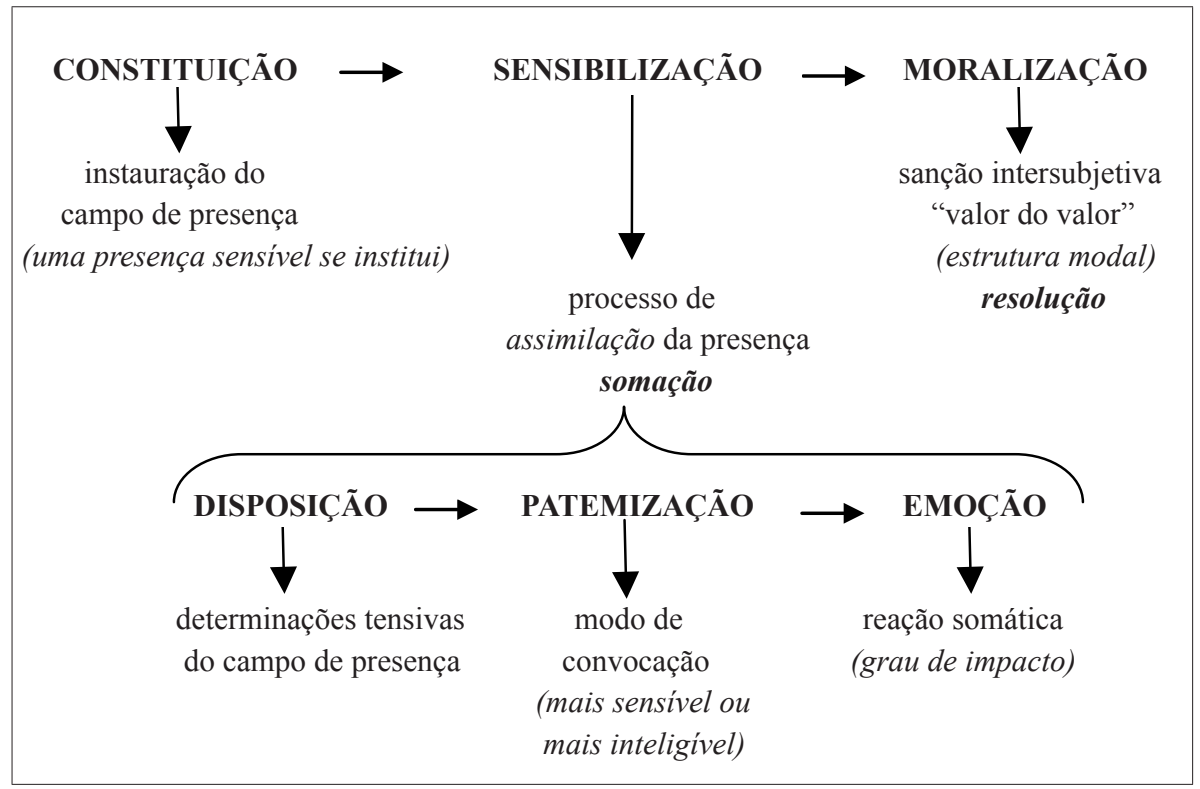

Esquema 4: Esquema passional canônico tensivizado (interpretação nossa a partir do esquema proposto em Semiótica das paixões, 1993).

Nessa interpretação de caráter prioritariamente tensivo, a percepção assume, como se vê, a primazia absoluta no processo de instauração da interação patêmica entre sujeito e objeto-valor e torna possível a apreensão e o exame não só da dinâmica sintáxica subjacente, mas também do regime de inflexões sob o qual ela se desenvolve. $\mathrm{O}$ percurso de configuração das paixões compreendido dessa maneira permite identificar o que determina a maior ou menor densidade de presença do sujeito e do objeto-valor da afetividade reciprocamente, o tipo de determinação tensiva própria a uma interação mais da ordem do sensível, ou mais da ordem do inteligível.

Essa perspectiva é semelhante às proposições de Jean-François Bordron (2002), para quem a percepção corresponde ao ato de enunciação, 
a um processo composto de três momentos: o indicial, referente à emergência de uma presença sensível no campo perceptivo do sujeito; o icônico, quando a presença sensível se organiza em formantes, ocupando uma certa extensão e tornando-se passível de um reconhecimento e uma identificação cognitivas; e o simbólico, responsável justamente por essa especificação, essa categorização da presença, atribuindo-lhe um sentido próprio.

Nosso interesse está, todavia, mais do que no processo de produção do sentido em si, nas regularidades sintáxicas da articulação do sensível com o inteligível, no momento de instauração das condições de emergência da interação patêmica, subjacentes à produção dos afetos. Importa-nos, portanto, poder oferecer um modelo de análise capaz de depreender a predicação tensiva que, como princípio organizador do campo de presença, dirige a ligação entre os sujeitos de determinada interação afetiva e convocam de maneira específica uma e outra dimensão. Desse modo, também a eficácia persuasiva dos afetos, a sua força de impacto sobre os sujeitos, passa a poder ser avaliada, assinalando, a partir desse ponto de vista analítico, tanto o papel de destaque da dimensão sensível e afetiva nos processos significantes, no percurso de geração da significação, quanto a possibilidade de um exame semiótico dessa atuação, da dimensão retórica dos enunciados.

\section{Do enunciado à enunciação: a dimensão passional dos textos}

Como vimos, quando o interesse pelas paixões surge na teoria, o nível de pertinência regente é ainda prioritariamente o do enunciado, excluindo do campo de interesse as questões próprias à enunciação que o produz. Isso talvez explique o fato de a análise semiótica dos afetos, conforme concebida até então, estabelecer uma relação próxima com a ação, com a estrutura narrativa, sendo desenvolvida sobretudo a partir da identificação de transformações passionais constituintes da identidade afetiva (modal) do sujeito apaixonado.

A perspetiva da ação, todavia, é, na teoria semiótica francesa, a da redução da complexidade discursiva, e a paixão, por sua vez, diz respeito à sobreposição, a dispositivos e dimensões provenientes de diferentes etapas do percurso gerativo. Como explica Fontanille (2007, p. 168): 
Se reduzimos o discurso enunciado unicamente à cena predicativa, só conservamos a dimensão narrativa e formal do discurso, e seu substrato axiológico, e perdemos de vista, ao mesmo tempo, tanto a dimensão do discurso em ato como as condições de emergência dos valores. Essa concepção sobre o discurso possibilitou os avanços teóricos e metodológicos dos anos 1970 e 1980, justamente porque ela reduzia o domínio de pertinência e purificava-o de todo efeito "subjetivo". Ao "objetivar" o discurso sob a forma de um simples enunciado, essa concepção tornava possível a articulação formal. Ela deve, atualmente, ser completada pela outra concepção que adota o ponto de vista do discurso em ato.

Com o advento da tensividade, do corpo-próprio, da preocupação em compreender as (pré-)condições de emergência e configuração da significação pela percepção, isso começa a se transformar, e a problemática da enunciação ganha força, ultrapassando o status de pressuposto lógico. É quando o devir passa a ocupar o primeiro plano na investigação dos processos de significação. Segundo chama a atenção Mancini (2007, p. 105), "essa perspectiva dinâmica parece revelar uma relação estreita entre os fluxos tensivos e a expressão de suas estabilizações efêmeras no nível discursivo"; trata-se, como explica a autora (Idem, p. 98), "da organização de um campo de presença, cuja manutenção de seu devir depende de uma organização particular do campo tensivo, organização esta tributária tanto da direção do ato perceptivo (foco), quanto de sua extensão (apreensão)". A noção de enunciação fica, dessa forma, atrelada à de percepção e à de presença, como responsável direta pela produção e estabelecimento desta última. Ela responde pela dinâmica que circunscreve e orienta a interação entre sujeito da percepção e objeto percebido.

Conforme aos desenvolvimentos contemporâneos da semiótica francesa, a nova interpretação do esquema passional canônico adota também essa ideia, buscando examinar as paixões, a configuração das interações afetivas, para além da identificação e descrição de códigos estereotipados. Interessa agora depreender o instante de sua emergência, da experiência que o afeto proporciona ao sujeito patêmico no universo da significação em ato. Ao assumir a perspectiva do devir, o percurso de análise sugerido procura, pois, dar conta das condições de geração 
dos afetos em todos os níveis do percurso gerativo, porque mais do que as paixões nos textos, importa compreender também a produção delas a partir dos textos, privilegiando a enunciação viva, não a passionalidade enunciada, mas aquela que é (re)criada nas estratégias enunciativas, no modo como o enunciador constrói seu enunciado, na maneira como ele estabelece o acesso do enunciatário ao conteúdo transmitido.

$\mathrm{Na}$ análise concreta da dimensão passional dos textos, da afetividade que eles suscitam na significação em ato, a fase da constituição será, por conseguinte, aquela do contato do enunciatário com o enunciado, da "posição" que ele passa a ocupar (mais próxima e subjetiva ou mais distante e objetiva) quando o conteúdo começa a se concretizar, a tomar forma, diante dele, instaurando um campo de presença. A sensibilização, como manifestante da dimensão passional dos textos, diz respeito aos procedimentos de configuração da interação entre o enunciatário e os atores do enunciado, portadores dos valores em questão; é a etapa de gerenciamento da tensão que define os graus de presença do objeto-valor da afetividade, o modo de envolvimento afetivo do sujeito da percepção, o enunciatário. Na microestrutura que a constitui, a disposição responde, portanto, pela determinação do acesso ao conteúdo, ao gerenciamento do ato perceptivo que caracteriza as especificidades do campo de presença com maior ou menor profundidade; tem a ver com as estratégias de apresentação, e consequentemente de interpretação, do conteúdo. A patemização, por sua vez, é a assimilação da tensão subjacente ao enunciado, à oposição dos valores semânticos de base, com o figural articulado à dimensão figurativa. É o momento da convocação mais sensível ou mais inteligível para a apreensão da presença. A emoção é a resposta, a manifestação da recepção das tensões, a instauração do elo - mais tônico ou mais átono, mais sensível ou mais inteligível - entre o enunciatário e os atores do enunciado. Para fechar a configuração dos estados de alma, vem a moralização, o momento no qual se concretiza e se manifesta, pela apreciação subjetiva do sujeito já sensibilizado, o "valor do valor", o valor que o enunciatário passa a atribuir aos valores dados pelo discurso, isto é, o afeto próprio ao estado de alma que então se institui. 


\section{Apontamentos finais}

Partir dessa outra forma de abordagem dos afetos, ou da dimensão passional dos enunciados, parece-nos válido por permitir uma investigação da função constitutiva dos estados de alma, ou seja, da junção (ou do modo de junção) que une o sujeito ao objeto, não apenas em sua pontualidade efetiva, como produto, mas em sua duração, como um percurso gerativo aspectualizado. Ademais, a proposição de um esquema passional canônico articulado em fases sucessivas de concretização discursiva afigurou-se como a melhor maneira de depreender e esboçar a organização estrutural da interação afetiva, da sua progressão, considerando tanto a produção do enunciado quanto a sua interpretação como atos de semiose. Não se trata, contudo, de apresentar um esquema a ser aplicado mecanicamente, mas sim um percurso de discretização do devir da relação intersubjetiva que delineia o efeito passional examinado. O que de fato importa é chamar a atenção do analista tanto às determinações sintáxicas subjacentes à emergência da interação afetiva em causa, e, com isso, à operacionalidade das noções emprestadas - de maneira peculiar, ou seja, semiotizada - da teoria fenomenológica, como percepção, presença, sensível e inteligível, quanto à complexificação que vai das primeiras somações (sensíveis) à resolução (inteligível), à produção do "valor do valor", o valor dado aos valores enunciados, base da intersubjetividade.

Para além do exame das paixões enunciadas, poder depreender e avaliar, a partir da análise dos textos, as condições de produção dos efeitos de sentido passionais nos parece um passo importante para a teoria, que passa a oferecer uma metodologia coerente para o estudo, dentro da perspectiva semiótica, não só da significação atualizada pelo enunciador, quando da produção do enunciado, mas inclusive da significação realizada pelo enunciatário, no instante do seu contato com o texto. É aí que, ancorados no discurso enunciado e manifestado por uma linguagem qualquer, e tomando-o como ponto de partida, temos as melhores condições de observar o modo como a tríade enunciador, enunciado, enunciatário interage no processo de geração do sentido. 


\section{Referências}

BEIVIDAS, W. A dimensão do afeto em semiótica: entre fenomenologia e semiologia. In: MARCHEZAN, R. C.; CORTINA, A.; BAQUIÃO, R. C. (Org.). A abordagem dos afetos na semiótica. São Carlos: Pedro \& João editores, 2011. p. 13-33.

BERTRAND, D. (Coord.). Actes sémiotiques. Bulletin, XI, n. 39, 1986. BERTRAND, D. Caminhos da semiótica literária. Trad. Grupo CASA, sob a coordenação de Ivã Carlos Lopes et al. Bauru: EDUSC, 2003.

BERTRAND, D. Da imperfeição. Trad. Ana Claudia de Oliveira. São Paulo: Hacker, 2002.

BERTRAND, D. De l'imperfection. Périgueux: Pierre Fanlac, 1987.

BERTRAND, D.; FONTANILLE, J. Semiótica das paixões. Dos estados de coisas aos estados de alma. Trad. Maria José Rodrigues Coracini. São Paulo: Ática, 1993.

BERTRAND, D.; FONTANILLE, J. Sémiotique des passions. Des états de choses aux états d'âme. Paris: Seuil, 1991.

BORDRON, J-F. Perception et énonciation dans l'expérience gustative. In: HÉNAULT, A. (Dir.). Questions de sémiotique. Paris: PUF, 2002. p. 639-665.

DISCINI, N. Um algoritmo da percepção: o sujeito do afeto. In: MARCHEZAN, R. C.; CORTINA, A.; BAQUIÃO, R. C. (Org.). A abordagem dos afetos na semiótica. São Carlos: Pedro \& João Editores, 2011. p. 149-172.

FONTANILLE, J. La base perceptive de la sémiotique. In: HELBO, André (Dir.). Dégres. Revue de synthèse à orientation sémiologique, n. 81, p. a1-a25, 1995.

FONTANILLE, J. Le désespoir. Actes Sémiotiques. Documents II, n. 16, Paris, CNRS, 1980.

FONTANILLE, J. Le schéma des passions. Protée, v. 21, n. 1, p. 33-41, 1993 b.

FONTANILLE, J. Le tumulte modal: de la macro-syntaxe à la microsyntaxe passionnelle. In: BERTRAND, D. (Coord.). Actes sémiotiques, Bulletin XI, n. 39, p. 12-31, 1986. 
FONTANILLE, J. Modulations passionnelles. In: WIKTOROWICZ, C. Algirdas J. Greimas et Jacques Fontanille, Sémiotique des passions. Des états de choses aux états d'âme. Études littéraires, v. 25, n. 3, p. 153-161, 1993a.

FONTANILLE, J. Semiótica do discurso. Trad. Jean Cristtus Portela. São Paulo: Contexto, 2007.

FONTANILLE, J. Sémiotique des passions. In: HÉNAULT, A. (Dir.). Questions de sémiotique. Paris: PUF, 2002. p. 601-637.

FONTANILLE, J. Sémiotique du discours. Limoges: PULIM, 1998. [2 $2^{\mathrm{a}}$ ed. ampliada publicada em 2003].

FONTANILLE, J. Sémiotique et littérature. Paris: PUF, 1999.

FONTANILLE, J. Vent'anni dopo. Studiare le passioni oggi. Trad. it. di Cristina Greco. E/C, 2012. Disponível em: <http://www.ec-aiss.it/ archivio/tipologico/autore.php>. Acesso em: 15 jan. 2013.

FONTANILLE, J.; ZILBERBERG, C. Tensão e significação. Trad. Ivã Carlos Lopes, Luiz Tatit e Waldir Beividas. São Paulo: Humanitas, 2001. GREIMAS, A. J. De la colère. Actes Sémiotiques. Documents III, n. 27, Paris, CNRS, 1981.

GREIMAS, A. J. De la nostalgie. Étude de sémantique lexicale. In: BERTRAND, D. (Coord.). Actes sémiotiques, Bulletin XI, n. 39, p. 5-11, 1986.

GREIMAS, A. J. Du sens II. Paris: Seuil, 1983.

GREIMAS, A. J. Pour une théorie des modalités. Langages, n. 43, p. 90-107, 1976.

GREIMAS, A. J. Pour une théorie des passions. Bulletin, n. 6, juin 1978. HÉNAULT, A. Le débat du 23 mai 1989 entre A. J. Greimas et Ricoeur sur la sémiotique des passions. In: . Le pouvoir comme passion. Paris: PUF, 1994. p. 189-216.

HÉNAULT, A. Structures aspectuelles du rôle passionnel. In: BERTRAND, D. (Coord.). Actes sémiotiques, Bulletin XI, n. 39, p. 3242, 1986. 
LANDOWSKI, E. Para uma semiótica sensível. Educação e realidade, v. 30, n. 2, 2005. Disponível em: <http://seer.ufrgs.br/educacaoerealidade/ article/view/12417>. Acesso em: 20 fev. 2016.

MANCINI, R. C. Dinamização nos níveis do percurso gerativo: canção e literatura contemporânea. 20-06. 191f. Tese (Doutorado) - Programa de Pós-Graduação em Semiótica e Linguística geral, FFLCH/USP, 2006.

MARSCIANI, F. Les parcours passionnels de l'indifférence. Actes sémiotiques. Documents VI, n. 53, 1984.

MARSCIANI, F. Note de lecture. Actes sémiotiques. Documents IV, n. $37,1982$.

PARRET, H. Eléments pour une typologie raisonnée des passions. Actes sémiotiques. Documents IV, n. 37, 1982.

PARRET, H. Les passions. Essais sur la mise en discours de la subjectivité. Bruxelles: Mardaga, 1986.

PORTELA, J. C. Conversations avec Jacques Fontanille. Alfa, n. 50, v. 1, p. 159-186, 2006. Disponível em: <http://seer.fclar.unesp.br/alfa/article/ view/1401/1101>. Acesso em: 4 mar. 2016.

TEIXEIRA, L. Da Imperfeição: um marco nos estudos semióticos. Galáxia, n. 4, p. 257-261, 2002. Disponível em: <http://revistas.pucsp. br/index.php/galaxia/article/view/1296/793>. Acesso em: 10 mar. 2016. THÜRLEMANN, F. L'admiration dans l'esthétique du XVIIe siècle. Actes Sémiotiques. Documents II, n. 11, Paris, CNRS, 1980. 